This is the author's final, peer-reviewed manuscript as accepted for publication. The publisher-formatted version may be available through the publisher's web site or your institution's library.

\title{
A comparison of non-violent, psychologically violent, and physically violent male college daters
}

Lundeberg, K. L., Stith, S. M., Ward, D. B., Penn, C. E.

\section{How to cite this manuscript}

If you make reference to this version of the manuscript, use the following information:

Lundeberg, K. L., Stith, S. M., Ward, D. B., Penn, C. E. (2004 A comparison of nonviolent, psychologically violent, and physically violent male college daters. Retrieved from http://krex.ksu.edu

\section{Published Version Information}

Citation: Lundeberg, K. L., Stith, S. M., Ward, D. B., Penn, C. E. (2004). A comparison of non-violent, psychologically violent, and physically violent male college daters. Journal of Interpersonal Violence, 19(10), 1191-1200.

Copyright: ( 2004 Sage Publications

Digital Object Identifier (DOI): doi:10.1177/0886260504269096

Publisher's Link: http://jiv.sagepub.com/content/19/10/1191

This item was retrieved from the K-State Research Exchange (K-REx), the institutional repository of Kansas State University. K-REx is available at http://krex.ksu.edu 
Running Head: Non-violent, psychologically violent, and physically violent college students

A Comparison of Non-Violent, Psychologically Violent, and Physically Violent Male College Daters

Lundeberg, K.L., Stith, S.M., Ward, D.B., Penn, C.E. (2004). A comparison of nonviolent, psychologically violent, and psychologically and physically violent male college daters. Journal of Interpersonal Violence, 19, 1191-1200. 


\begin{abstract}
This brief report explores dating violence by comparing three groups of male college students (non-abusive, psychologically abusive only, and physically abusive). These men were compared on measures of impulsivity, problems with alcohol, life satisfaction, anger management skills, history of witnessing abuse, history of experiencing abuse, and relationship satisfaction. Data for this analysis were obtained from a sample of 115 male college students. Differences between the three groups of men were found in the levels of problems with alcohol, relationship satisfaction, and anger management skills. Anger management skills best differentiated the three groups of men, leading to the conclusion that dating violence prevention and intervention strategies with male college students should address anger management skills.
\end{abstract}


A Comparison of Non-Violent, Psychologically Violent, and Physically Violent Male College Daters

This report focuses on understanding how levels of impulsivity, problems with alcohol, satisfaction with life, anger management skills, relationship satisfaction, and witnessing or experiencing violence as a child can differentiate college men who are physically abusive (PA) from those who are psychologically abusive, but not physically abusive (PSY) and from those who are neither psychologically nor physically abusive (NA). Understanding factors that differentiate these men, especially in dating populations, can aid in the assessment and treatment of individuals and couples at risk for physical aggression and can further our understanding of developmental processes that influence relationship violence (Murphy \& Hoover, 1999).

Three previous studies, Stets (1990), Sugarman and Hotaling (1989), and Sugarman, Aldarondo, and Boney-McCoy (1996), examined differences between non-abusive, psychologically abusive, and physically abusive men. These studies were based on the 1976 and 1985 National Family Violence Surveys (NFVS), and reported only on couples currently in intact marital or cohabiting relationships. To our knowledge, no studies to date have looked at what distinguishes PA, PSY, and NA men in dating relationships.

Lewis and Fremouw (2001) reviewed literature on variables associated with dating violence. They found that experiencing child abuse, witnessing parental violence, and alcohol and drug use appear related to the perpetration of dating violence. However, the authors suggest that further investigation is necessary due to the array of discrepant findings between studies. In this study, we expected these variables to differentiate between PA, PSY, and NA groups.

There is a dearth of research examining impulsivity and dating violence. However, in their typology work of maritally violence men, Holtzworth-Munroe et al. (2000) found that both 
generally violent-antisocial batterers and borderline-dysphoric batterers are significantly more impulsive than nonviolent husbands and family only batterers. Therefore, we were interested in determining if levels of impulsivity would differentiate the three groups of college men.

Research indicates that women in physically abusive relationships report that as the physical abuse they experience decreases, their overall self-reported life satisfaction improves (McNamara, Ertl, Marsh, \& Walker, 1997). Because there is a dearth of literature on the overall life satisfaction of males who perpetrate physical and psychological abuse we were interested in determining if levels of life satisfaction would differentiate the groups.

Dye and Eckhardt (2000) found that college students who were violent towards their partner reported expressing more anger-related behaviors and exhibited less control over anger expression than nonviolent participants. Therefore, we anticipated that individuals with less effective anger management skills would be found in the more aggressive groups.

Individuals with lower levels of relationship satisfaction perpetrate more violence than those who report higher satisfaction (O’Leary, Malone, \& Tyree, 1994). The 1976 NFVS (Sugarman \& Hotaling, 1989) found that physically aggressive men had significantly more marital conflict than the verbally aggressive and the non-violent groups. Thus, we anticipated that the level of relationship satisfaction would differentiate the three groups of college men.

\section{METHOD}

\section{Participants}

Participants were a convenience sample of male undergraduate students $(n=115)$ at a major Southeastern university campus. Four percent were freshmen, 22\% were sophomores, 33\% were juniors, and $39 \%$ were seniors. In terms of ethnicity, $86 \%$ were Caucasian, $4 \%$ were African American, $2 \%$ were Asian, and the remaining subjects were "Other” races. The 
undergraduate enrollment profile at that university was 85\% Caucasian, 4\% African American, 2\% International and $8.4 \%$ other. Therefore, this sample appears to be representative of the general university community from which the sample was drawn. There was a wide range of family income represented among the respondents, but almost half of the respondents (49\%; $n=$ 56) reported having family income of $\$ 80,000$ or more.

\section{Measures}

Conflict Tactics Scale, Revised (CTS2); (Straus, Hamby, Boney-McCoy, \& Sugarman, 1996). The CTS2 is the most widely used measure of partner violence. Participants used two of the five subscales, Psychological Aggression (8 items) and Physical Assault (12 items) to report whether they had committed the act in question not at all to more than 20 times during the past year. Scores were computed by summing ratings of the items comprising each subscale. Cronbach’s alpha reliability for this sample on the subscales ranged from .78 to .85. Each participant reported on his own behavior with his current dating partner during the past year.

History of Witnessing or Experiencing Physical Abuse. Both of these variables were dichotomous. Participants were considered to have experienced physical abuse if they reported that they had "ever received severe physical discipline (such as hitting, punching, slapping, or beating).” They were considered to have witnessed abuse if they reported that they had “witnessed any type of parental violence (father to mother, mother to father or mutual violence).”

The Impulsiveness Scale; (Borgatta, 1965). This 5-item scale includes items such as, "My interest shifts quickly from one thing to another," and, "I usually act on the spur of the moment." High scores indicate higher levels of impulsiveness. Cronbach’s reliability for this sample is .62.

The Satisfaction with Life Scale (SWLS); (Diener, Emmons, Larsen \& Griffin, 1985). The SWLS is used to assess global life satisfaction, asking respondents five questions about their 
overall judgment of their lives (e.g., "if I could live my life over, I would change almost nothing"). Answers are based on a 5-point scale ranging from "Strongly Disagree" to "Strongly Agree.” Cronbach alpha reliability of this scale for participants in this study is .88.

The Rutgers Alcohol Problem Index (RAPI); (White \& Labouvie, 1989). The RAPI assesses for alcohol problems in adolescent/young adult populations. The 23-item short form used in this study asks, "How many times did the following things happen to you while you were drinking alcohol or because of your alcohol use over the last six months?” Choices range from "never" to "more than ten times". One item is "How many times were you not able to do your homework or study for a test?” Cronbach alpha reliability for this sample is .94.

Revised Dyadic Adjustment Scale (RDAS); (Busby, Crane, Larson, \& Christensen, 1995). This scale is a 14-item instrument based on the original 32-item Dyadic Adjustment Scale (Spanier, 1976). A sample question from RDAS is “How often do you and your partner quarrel?” Cronbach alpha reliability for participants in the present study is .83.

The Anger Management Scale (AMS); (Stith \& Hamby, 2002). The AMS assesses specific cognitions and behaviors that can increase or decrease anger in relationships and therefore influence the respondent's level of partner violence. The AMS has four subscales. Cronbach reliabilities for this study for these scales are .78 for "Escalating Strategies,” .85 for “Negative Attributions,”.72 for "Self-Awareness,” and .67 for "Calming Strategies."

\section{Procedure}

Professors were asked to distribute a survey examining college student dating relationships to their undergraduate students in Human Development, Psychology, Military Science, Business, and Engineering classes. Students were asked to complete the survey without putting any identifying information on the survey to preserve their anonymity. Of the 132 male 
subjects who completed surveys, 118 reported that they were presently in or had been in a relationship that lasted one month or more. Three of the subjects were missing data regarding their use of abuse; therefore, this study focuses on the remaining 115 men.

Male respondents were separated into groups based on the following criteria. The PA group ( $n=38$ ) consisted of men who self-reported that they had committed one or more act of physical abuse and one or more act of psychological abuse on the CTS2. No men reported any acts on the physical abuse scale without also reporting acts on the psychological abuse scale. The most frequent physical abuse items reported were grabbing partner $(n=23)$ and shoving partner ( $n=17)$. Five men reported using a knife at least once in the past year and five men also reported choking their partner within the past year. PSY abusive males $(n=44)$ reported one or more act on the psychological abuse subscale of the CTS2 in the previous year but no act of physical abuse. The most frequent psychological acts reported were swearing at partner $(n=26)$, shouting at partner $(n=24)$, and stomping out of the room $(n=24)$. Finally, the NA group $(n=33)$ reported no acts of psychological or physical abuse in the past year.

\section{RESULTS}

We first performed chi-squares to test the equality of the groups in regards to year of education, ethnicity, and family income. There were no significant differences between the groups on these variables, or on other demographic variables (mother's education, father's education, and parent's marital status).

Next, analyses were run to determine which variables differentiated the three groups of men. Since the witnessing and experiencing family of origin abuse variables were dichotomous, a Chi-square analysis was used. The analysis revealed no differences between the three groups on having either witnessed or experienced family of origin abuse $\left(x^{2}=.046, p=.98\right)$. 
The remaining variables were included in a multivariate analysis of variance (MANOVA) (Table 1), which revealed significant main effects among the three groups of males, $F(10,216)=7.28, p<.001$. Post hoc one-way analyses of variance (ANOVA) revealed significant differences among the three groups of males on problems with alcohol, $F(2,112)=$ 8.92, $p<.001$; anger management skills, $F(2,112)=32.06, p<.001$; and relationship satisfaction $F(2,112)=3.50, p<.05$.

\section{Insert Table 1}

There were significant differences between the groups on problems with alcohol, $F(2$, $112)=8.92, p<.001$. The mean score for the PA group $(M=1.87)$ was significantly higher $(p<$ $.01)$ than the PSY group $(M=1.46)$ and the NA group $(M=1.32, p<.001)$. No differences emerged between the NA and the PSY groups.

The level of anger management skills was the only variable to differentiate all three groups of men, $F(2,112)=32.06, p<.001$. The NA group scored significantly higher $(M=3.23$, $p<.05)$ than the other two groups. Furthermore, the PSY group scored significantly higher $(M=$ 2.95, $p<.001)$ than the PA group $(M=2.74)$.

There were significant differences between the groups on relationship satisfaction $F(2$, $112=3.50, p<.05$. The NA males scored significantly higher $(M=4.35, p<.05)$ than the PA group $(M=4.05)$. The PSY group was not significantly different than either of the other groups.

Since the anger management skills differentiated all three groups further analysis was preformed to determine which subscales were most important in discriminating groups. Again, a MANOVA was performed which found a significant overall effect, $F(8,218)=8.86, p<.001)$ (Table 2). Post hoc one-way ANOVA's revealed significant differences among the groups on the escalating strategies, $F(2,112)=31.58, p<.001$; negative attributions, $F(2,112)=16.23$, $p<$ 
.001 ; and self-awareness subscales, $F(2,112)=5.54, p<.01$; but not on the calming strategies subscale.

\section{Insert Table 2}

All three groups differed from each other on escalating strategies $(p<.01)$. The PA group scored significantly higher $(p<.001)$ than the other two groups on the negative attributions subscale. The NA and PSY groups were not significantly different. On the self-awareness subscale, only the PA group and the NA group differed significantly $(p<.01)$. The latter group scored significantly higher.

\section{DISCUSSION}

Overall, the variables in this study were able to differentiate the three groups of men, however, the groups did not differ on impulsivity, satisfaction with life, or on witnessing or experiencing violence as children. It is possible that because the group was so homogenous these factors were not important discriminators. In addition, the low reliability of the measure of impulsivity may have reduced its effectiveness.

There were significant differences among the groups on relationship satisfaction. PA men had significantly lower relationship satisfaction than NA males. These results support previous research, but do not, of course, indicate whether abuse leads to lower relationship satisfaction or if lower relationship satisfaction leads to abuse.

Significant differences were also found on the problems with alcohol measure. The results indicate that male college students who report using physical violence against their partners also report significantly higher negative consequences as a result of their alcohol use. It appears that physical and psychological abuse in dating relationships needs to be considered in any response to problem drinking among college men. 
All three groups were significantly different from one another on the Anger Management Scale. It appears that there was a continuum with those who were better at managing their anger being non-abusive, those with moderate levels of anger management skills being psychologically abusive, and those with the poorest anger management skills being physically abusive. The aspects of anger management that seemed most important were in the respondent's tendency to use escalating strategies such as raising his voice when arguing with his partner,fighting back when his partners “pick a fight," and also his tendency to apply negative attributions to his partner’s behaviors such as believing that "My partner likes to make me mad, or "My partner does things just to annoy me.” The NA men were more likely to be aware of their anger at earlier stages. They were more likely to agree with statements like, "I recognize when I am beginning to get angry at my partner" and they were more able to recognize when they were "about to lose my temper at my partner" than were PA males. There did not seem to be any differences among the three groups in their abilities to use calming strategies, such as taking a time out to control anger or taking a break from their partners.

\section{Limitations}

There are several limitations with this study that need to be addressed. First, the sample is fairly homogenous with most of the participants being Caucasian, and therefore the findings cannot be generalized to more diverse groups. Second, although some relationships between variables and one's affiliation with a group (NA, PSY, or PA) were revealed in this study, the results do not afford us with any information about what, if any, causal relationships might be present. The association may be present because of other intervening variables, and even if the association were causal, further research is needed to understand in which direction the causal arrow points. Third, results were based on men's self-report of their behaviors. Evidence 
suggests that male partners often underreport the occurrence of relationship aggression (Stets \& Straus, 1992). Furthermore, given that this was a convenience sample, it is possible that many abusive men chose not to participate. It is also possible that differences may be an artifact of the tendency of some participants to be more likely than others to admit to "bad behavior" (physical violence, alcohol abuse, and lack of anger management skills) and that these men all ended up in the "physically violent group." Finally, this study was a secondary analysis of data collected in a previous investigation (Stith \& Hamby, 2002). Thus, other important variables were not examined. For example, factors related to the men's use of power and control tactics were not examined in this study. It is possible that high levels of power and control tactics might be even more important in differentiating these three groups of college men than were the variables included in this investigation, but we were not able to examine these factors in this study. Implications for Practice

While there continues to be a debate in the field as to whether teaching anger management skills is an effective way to reduce male battering (Rosenthal \& McDonald, 2003), this study seems to suggests, at least in college student populations, that men with less effective anger management skills are more likely to perpetrate both psychological and physical violence than are those with more effective skills. This suggests the need for a psychoeducational component when treating physically and emotionally abusive men. It also appears that this educational component needs to focus on reducing the participants' use of escalating strategies and negative attributions and increasing their use of self-awareness strategies. Furthermore, college students with drinking problems may benefit from classes on handling conflict and dealing with anger to prevent psychological and physical aggression. 
TABLE 1:Means, Standard Deviations, and Group Comparison on Study Measures

\begin{tabular}{|c|c|c|c|c|}
\hline Measure & $\begin{array}{c}\text { Non- } \\
\text { Abusive } \\
n=33 \\
M(\mathrm{SD})\end{array}$ & $\begin{array}{c}\text { Psychologically } \\
\text { Abusive } \\
n=44 \\
M(\mathrm{SD}\end{array}$ & $\begin{array}{c}\text { Physically/psychologically } \\
\text { Abusive } \\
n=38 \\
M(\mathrm{SD} \\
\end{array}$ & $\begin{array}{l}\text { F-Test } \\
(2,112)\end{array}$ \\
\hline Impulsivity & $\begin{array}{c}1.30(1.31) \\
\mathrm{a}\end{array}$ & $\begin{array}{c}1.70(1.53) \\
\mathrm{a}\end{array}$ & $\begin{array}{c}2.13(1.55) \\
\mathrm{a}\end{array}$ & 2.79 \\
\hline SWLS & $\begin{array}{c}5.22(1.03) \\
a\end{array}$ & $\begin{array}{c}4.63(1.27) \\
\mathrm{a}\end{array}$ & $\begin{array}{c}4.85(1.30) \\
\mathrm{a}\end{array}$ & 2.24 \\
\hline RAPI & $\begin{array}{c}1.32(.49) \\
\mathrm{a}\end{array}$ & $\begin{array}{c}1.46(.46) \\
\mathrm{a}\end{array}$ & $\begin{array}{c}1.87(.74) \\
b\end{array}$ & $8.92 * *$ \\
\hline RDAS & $\begin{array}{c}4.35(.46) \\
\mathrm{a}\end{array}$ & $\begin{array}{c}4.08(.53) \\
\text { a, b }\end{array}$ & $\begin{array}{c}4.05(.57) \\
\text { b }\end{array}$ & $3.50 *$ \\
\hline AMS & $\begin{array}{c}3.23(.27) \\
\mathrm{a}\end{array}$ & $\begin{array}{c}2.95(.28) \\
b\end{array}$ & $\begin{array}{c}2.73(.24) \\
\quad \mathrm{c}\end{array}$ & $32.06 * *$ \\
\hline
\end{tabular}

Note. Items with different subscripts are significantly different .

${ }^{*} \mathrm{p}<.05 .{ }^{*} \mathrm{p}<.001$

Table 2: Means, Standard Deviations and Group Comparison on Anger Management Scale

\begin{tabular}{lcccc}
\hline \multicolumn{1}{c}{ Measure } & Non- & Psychologically & Physically/psychologically & F-Test \\
& Abusive & Abusive & Abusive & $(2,112)$ \\
& $n=33$ & $\mathrm{n}=44$ & $\mathrm{n}=38$ & \\
& $M(\mathrm{SD})$ & $M(\mathrm{SD})$ & $M(\mathrm{SD})$ & \\
\hline 15 item Escalating & $1.81(.38)$ & $2.30(.37)$ & $2.54(.42)$ & $31.58^{* *}$ \\
Strategies & $\mathrm{a}$ & $\mathrm{b}$ & $\mathrm{C}$ & \\
7 item Negative & $1.32(.30)$ & $1.56(.43)$ & $1.99(.70)$ & $16.23^{* *}$ \\
Attributions & $\mathrm{a}$ & $\mathrm{a}$ & $\mathrm{b}$ & \\
6 item Self- & $3.49(.45)$ & $3.31(.41)$ & $3.15(.42)$ & $5.54^{*}$ \\
Awareness & $\mathrm{a}$ & $\mathrm{a}, \mathrm{b}$ & $\mathrm{b}$ & \\
8 item Calming & $2.73(.52)$ & $2.71(.45)$ & $2.70(.40)$ & .07 \\
Strategies & $\mathrm{a}$ & $\mathrm{a}$ & $\mathrm{a}$ & \\
\hline
\end{tabular}

Note. Items with different subscripts are significantly different .

${ }^{*} \mathrm{p}<.01 .{ }^{* *} \mathrm{p}<.001$. 


\section{REFERENCES}

Borgatta, E. F. (1965). A short test of personality: The S-ident form. Journal of Educational Research, 58(10), 453-456.

Busby, D. M., Crane, D. R., Larson, J. H., \& Christensen, C. (1995). A revision of the Dyadic Adjustment Scale for use with distressed and nondistressed couples: Construct hierarchy and multidimensional scales. Journal of Marital and Family Therapy, 21, 289-308.

Diener, E., Emmons, R. A., Larsen, R. J., \& Griffin, S. (1985). The Satisfaction with Life Scale. Journal of Personality Assessment, 49, 71-75.

Dye, M., \& Eckhardt, C. I. (2000). Anger, irrational beliefs, and dysfunctional attitudes in violent dating relationships. Violence \& Victims, 15, 334-350.

Holtzworth-Munroe, A., Meehan, J. C., Herron, K., Rehman, U., \& Stuart, G. L. (2000). Testing the Holtzworth-Munroe and Stuart (1994) batterer typology. Journal of Consulting \& Clinical Psychology, 68, 1000-1019.

Lewis, S.F. \& Fremouw, W. (2000). Dating violence: A critical review of the literature. Clinical Psychology Review, 21, 1, 105-127.

McNamara, J. R., Ertl, M. A., Marsh, S., \& Walker, S. (1997). Short-term response to counseling and case management intervention in a domestic violence shelter. Psychological Reports, $81,1243-1251$.

Murphy, C. M., \& Hoover, S. A. (1999). Measuring emotional abuse in dating relationships as a multifactorial construct. Violence and Victims, 14, 39-53.

O'Leary, K. D., Malone, J., \& Tyree, A. (1994). Physical aggression in early marriage: Prerelationship and relationship effects. Journal of Consulting \& Clinical Psychology, 62, 594-602. 
Rosenthal, L. \& McDonald, S. (2003). Seeking justice: A review of the second report of the defense task force on domestic violence. Violence Against Women, 9, 1153-1161.

Spanier, G.B. (1976). Measuring dyadic adjustment: New scales for assessing the quality of marriage and similar dyads. Journal of Marriage and the Family, 38, 15-28.

Stets, J. E. (1990). Verbal and physical aggression in marriage. Journal of Marriage and the Family, 52, 501-514.

Stets, J.E., \& Straus (1992). Gender differences in reporting marital violence and its medical and psychological consequences. In M.A. Straus \& R. Gelles (Eds.), Physical violence in American families: risk factors and adaptations to violence in 8,145 families (pp.151165). New Brunswick, NJ: Transaction Books.

Stith, S. M., \& Hamby, S. L. (2002). The Anger Management Scale: Development and preliminary psychometric properties. Violence and Victims, 17(4), 383-402.

Straus, M. A., Hamby, S. L., Boney-McCoy, S., \& Sugarman, D. B. (1996). The revised Conflict Tactics Scales (CTS2): Development and preliminary psychometric data. Journal of Family Issues, 17, 283-316.

Sugarman, D. B., \& Hotaling, G. T. (1989). Violent men in intimate relationships: An analysis of risk markers. Journal of Applied Social Psychology, 19, 1034-1048.

Sugarman, D. B., Aldarondo, E., \& Boney-McCoy, S. (1996). Risk marker analysis of husbandto-wife violence: A continuum of aggression. Journal of Applied Social Psychology, 26, 313-337.

White, H. R., \& Labouvie, E. W. (1989). Towards the assessment of adolescent problem drinking. Journal of Studies on Alcohol, 50, 30-37. 